\title{
Reliability and Validity of the Perceived Neighborhood Food Environment Scale
}

\author{
Mihono Komatsu ${ }^{1}$, Rie Akamatsu ${ }^{2}$, Emi Yoshii ${ }^{3}$ \& Mika Saiki ${ }^{1}$ \\ ${ }^{1}$ Former Graduate School of Humanities and Sciences, Ochanomizu University, Tokyo, Japan \\ ${ }^{2}$ Faculty of Core Research, Natural Science Division, Ochanomizu University, Tokyo, Japan \\ ${ }^{3}$ Graduate School of Humanities and Sciences, Ochanomizu University, Tokyo, Japan \\ Correspondence: Rie Akamatsu, Otsuka 2-1-1, Bunkyo-ku, Tokyo 112-8610, Japan. Tel: 81-3-5978-5680. E-mail: \\ akamatsu.rie@ocha.ac.jp
}

Received: February 13, 2020 Accepted: April 20, 2020 Online Published: April 30, 2020

doi:10.5539/jedp.v10n1p71 URL: http://doi.org/10.5539/jedp.v10n1p71

\begin{abstract}
In order for people to make healthy food choices, the food environment needs to be improved and residents must be aware of it. This research aimed to assess the reliability and validity of the Perceived Neighborhood Food Environment (PNFE) scale, which assesses participants' perceptions of the present condition of their food environment. Data from the Survey on the Present Condition and Consciousness of Dietary Education conducted by the Cabinet Office of Japan in 2010 were used, and 1,853 participants were included. We performed an exploratory factor analysis (EFA) and confirmatory factor analysis (CFA), and examined internal consistency and the criterion-related validity of the PNFE. The PNFE comprised two factors: "regional food culture" (5 items) and "physical availability of food" (3 items). The model fitness indices were good (GFI = .97, AGFI $=.95, \mathrm{CFI}=.96$, RMSEA = .073) and Cronbach's $\alpha$ was .77 for the whole scale. Reasonable results were obtained for criterion-related validity. We confirmed the reliability and validity of the PNFE scale. By utilizing the scale for future research in other countries, its reliability and validity for a wider range of residents will likely be confirmed. In addition, consideration should be given to the items used for confirming the validity of the scale in the next study to ensure that they are appropriate for other countries included in the research.
\end{abstract}

Keywords: food environment, public health, reliability, social capital, validity

\section{Introduction}

Food choices and eating habits are influenced by one's social environment in addition to personal preferences, knowledge, attitudes, and beliefs; therefore, environmental improvement is being undertaken for health promotion (Ministry of Health, Labour and Welfare, 2012; Public Health England, 2018). The density of supermarkets and grocery stores and the convenience of everyday shopping are related to healthy eating habits (Iwama, Asakawa, Tanaka, \& Komaki, 2016; Moore, Diez Roux, Nettleton, \& Jacobs, 2008; Yoshiba et al., 2015); thus, it is necessary to ensure that it is easy to purchase food items locally, prior to undertaking food environment improvements. Not only geographical but also economic factors affect declines in food access (Yakushiji, Takahashi, \& Tanaka, 2013). Observational studies at retail food stores have shown that availability is also an important element of food access (Cannuscio et al., 2013; Glanz et al., 2016).

Improving the food environment alone will not lead to healthy eating behaviors unless residents perceive these improvements. Green and Glanz (2015) developed a scale for assessing perceived food environment, the Perceived Nutrition Environment Measures Survey (NEMS-P). The scale measures three factors: community nutrition environment, consumer nutrition environment, and home food environment. The community nutrition environment is measured according to the distance to the most frequented grocery stores and restaurants; consumer nutrition environment refers to the availability and price of foods and dishes at grocery stores and restaurants. The home food environment is evaluated based on the types of food available at home. For these three factors, only the NEMS-P evaluates access to food. However, community ties involving food also affect eating behavior (Health Sciences Council, 2012). Therefore, we need a scale for the food environment that includes community ties, such as interaction with one's neighborhood or thoughts regarding the local culture.

In Japan, the food environment includes not only access to food itself but also community-based social resources. 
The Cabinet Office of Japan has conducted surveys on shokuiku (food and nutrition education/promotion) and investigated features of the food environment, including community-based social resources (Office for Shokuiku Promotion, 2011). These surveys, however, did not assess the reliability and validity of the scale used. To address this gap, this study examined the reliability and validity of the Perceived Neighborhood Food Environment (PNFE) scale.

\section{Method}

\subsection{Participants}

Data from The Survey of the Current Status and Awareness of Shokuiku, a study conducted by Japan's Cabinet Office in December 2010 (Office for Shokuiku Promotion, 2011), were analyzed. The participants were selected using a two-stage stratified random sampling. First, 210 cities - the same cities used in Japan's National Census - were indentifid. Then, 10-17 samples were chosen randomly from each city-with total participants approaching 3,000 - depending on the size of each city. The number of responses was $1,853(61.8 \%)$; men and women aged 20 years or older responded during individual interviews. Regarding secondary data usage, we received permission from the Social Science Japan Data Archive, Center for Social Research and Data Archives, Institute of Social Science, the University of Tokyo.

\subsection{Materials}

The PNFE consists of eight items selected by the food education committee organized by the Cabinet Office (Table 1). Participants were asked, "What do you think about the region and people in the region where you live? Please consider the 'region' as from the elementary/junior high school district to the municipal township." They were then asked to choose from responses scored 1 to 5 for each item: disagree, relatively disagree, no opinion, relatively agree, and agree.

Quality of life related to diet was assessed using the Subjective Diet-related Quality of Life (SDQOL) scale (Ainuki, Akamatsu, Hayashi, \& Takemi, 2012). This four-item questionnaire assesses "your ordinary diet" and includes statements such as "mealtime is enjoyable"; responses were scored on a similar five-point scale as the PNFE, from $1=$ disagree to $5=$ agree.

Additionally, basic attributes (gender, age, number of people living together, city size of the residential area), frequency of balanced diet ("How often do you eat a well-balanced Japanese diet more than twice a day?") (Kakutani, Kamiya, \& Omi, 2015; Kurotani et al., 2016), and subjective health ratings were assessed.

\subsection{Data Analysis}

Item analysis, exploratory factor analysis (EFA), confirmatory factor analysis (CFA), and internal consistency assessment were undertaken. Item analysis confirmed that there were no biased responses (i.e. selecting one option more than $75 \%$ of the time). EFA was conducted using the maximum likelihood method and promax rotation; the number of factors was defined based on the latent root criterion (eigenvalue $>1.0$ ). CFA, which was conducted for construct validation, employed the Goodness of Fit Index (GFI), Adjusted GFI (AGFI), Comparative Fit Index (CFI), Root Mean Square Error of Approximation (RMSEA), and Akaike's Information Criterion (AIC) as fitness indicators (Oshio, 2008). In the factor analysis, the missing values on each item were replaced with median values. For each item, less than $1 \%$ of values were missing. The internal consistency was measured with Cronbach's alpha.

Criterion-related validity was examined using nine external criteria: SDQOL, subjects' attributes, frequency of balanced diet, and subjective health. In the analyses using the SDQOL, Spearman's correlations were used. Cases missing even one SDQOL item were excluded from the analysis. Associations with other items were examined using Mann-Whitney U or Kruskal-Wallis tests and Bonferroni-corrected multiple comparisons.

For the analysis, we used IBM SPSS Statistics 20.0 for Windows (IBM Japan, Ltd.) and SPSS Amos 19.0 for Windows (Japan EB Corporation); the significance level was set at $\mathrm{p}<5 \%$ (two-tailed).

\subsection{Ethical Standards}

This study was approved by the Ethics Special Committee of Ochanomizu University Biomedical Research (No. 2017-2). Written informed consent was obtained from all participants.

\section{Results}

\subsection{Participants' Characteristics}

Of the 1,853 respondents, $44.4 \%(\mathrm{n}=823)$ were men and $55.6 \%(\mathrm{n}=1030)$ were women. Participants were aged 20-94 years, with a median of 54 years; 1708 people $(92.2 \%)$ lived with at least one other person in the household and $41.6 \%$ lived in midsize cities. 


\subsection{Item Analysis and Factor Analysis}

There were no inter-item correlations of $r_{s} \geq$.7. EFA was performed using all eight items and two factors were extracted. No items had factor loadings $<.40$ or elevated cross-loadings $(\geq .40)$. Based on item content, the two factors were named "regional food culture" and "physical availability of food" (Table 1).

In the CFA examining the model obtained by the EFA, the fit indexes were less than satisfactory (GFI $=.95$, AGFI $=.90, \mathrm{CFI}=.92, \mathrm{RMSEA}=.10, \mathrm{AIC}=403.78)$; therefore, we modified the factor model by checking the error correlations. Good fit index values were obtained in the model wherein an error correlation was set between "atmosphere that cherishes food culture, tradition, seasonality, etc." and "people's interest in the nutritional and safety aspects of food is high" (see Table 1). This error correlation can be explained by the similarities between the items. This model was therefore confirmed as appropriate for explaining the structure of the scale.

Table 1. Perceived Neighborhood Food Environment: Items and Factor Loadings $(\mathrm{n}=1853)$

\begin{tabular}{|c|c|}
\hline Factor Loadings & \\
\hline Exploratory & \\
\hline $1 \quad 2$ & \\
\hline
\end{tabular}

Factor 1: Regional Food Culture $(\alpha=.76)$

1. In this area, there is an atmosphere that cherishes food culture, tradition, seasonality, etc.

2. In this area, I can obtain necessary information on food.

3. Activities and events focusing on food are active in this area.

4. Regional people's interest in the nutritional and safety aspects of food is high.

5. In this area, I can exchange foods with others easily, such as through sharing.

$\begin{array}{ccc}.71 & .02 & .61^{\mathrm{a}} \\ .68 & .06 & .79 \\ .66 & -.09 & .63 \\ .59 & .15 & .57^{\mathrm{a}} \\ .58 & -.15 & .50\end{array}$

Factor 2: Physical Availability of Food $(\alpha=.75)$

6. In this area, it is easy to obtain a nutritionally balanced meal, for example, based on staple foods, main dishes, side dishes, etc.

7. This area is blessed with trustworthy shops and producers in terms of food safety.

8. In this area, I can purchase the necessary ingredients at supermarkets and food stores, and I have transportation methods to go shopping, so I do not feel inconvenienced in everyday shopping.

Note. Two factors, eight items $(\alpha=.77$, Distributed explanation rate: $47.0 \%, \mathrm{GFI}=.97, \mathrm{AGFI}=.95, \mathrm{CFI}=.96, \mathrm{RMSEA}=.073$, $\mathrm{AIC}=231.20$ ), Factor extraction method: Maximum likelihood method, Rotation method: Promax rotation

${ }^{\mathrm{a}}$ Error correlation: a-a (.39)

\subsection{Reliability and Validity}

For the total scale and each subscale, Cronbach's $\alpha$ coefficients were acceptable (total scale: .77; "regional food culture": .76; "physical availability of food": .75). The median of the total score (25th and 75th percentile values) was 29 (26, 32; range: 8-40), while those for "regional food culture" and "physical availability of food" were 16 $(13,19$; range: 5-25) and $14(12,15$; range: 3-15), respectively. Correlations between the total and the subscales were investigated using Spearman's correlations. The total scale had a strong positive correlation $\left(r_{s}=.91, \mathrm{p}<.001\right)$ with "regional food culture" and a positive correlation $\left(r_{s}=.67, \mathrm{p}<.001\right)$ with "physical availability of food". The subscales had a weak positive correlation $\left(r_{s}=.33, \mathrm{p}<.001\right)$.

The SDQOL scale had weak positive correlations with the total PNFE scale $\left(r_{s}=.28, \mathrm{p}<.001\right)$ and the two subscales (regional food culture: $r_{s}=.23, \mathrm{p}<.001$, physical availability of food: $r_{s}=.25, \mathrm{p}<.001$ ). The Cronbach's $\alpha$ of the SDQOL was .73, and the median score (25th and 75th percentile) was 17 (15, 19; range: 4-20).

We examined the PNFE scores by participant attributes, frequency of balanced diet, and subjective health (Table 2). Respondents living with at least one other person had higher total $(\mathrm{p}=.026)$ and "regional food culture" $(\mathrm{p}=.005)$ scores than those living on their own. Regarding city size, we found differences between all groups $(p<.001)$; however, the results of multiple comparisons differed between subscales. With regard to "regional food culture", 
persons in the Tokyo ward area scored lower than did those in middle cities, small cities, and municipalities (Bonferroni multiple comparison: $\mathrm{p}<.05$ ). Conversely, for "physical availability of food", municipal residents scored lower than did those in government-designated cities, middle cities, and small cities (Bonferroni multiple comparison: $\mathrm{p}<.05)$. For frequency of balanced diet, those who ate it "almost every day" had higher scores ( $p$ $<.001)$, and for subjective health, persons in "very good" health scored higher $(\mathrm{p}<.001)$.

Table 2. Score of Perceived Neighborhood Food Environment: Criterion-Related Validity

\begin{tabular}{|c|c|c|c|c|c|c|c|}
\hline & \multirow[t]{2}{*}{$\mathrm{n}(\%)$} & \multicolumn{2}{|l|}{ Total } & \multicolumn{2}{|c|}{ Regional Food Culture } & \multicolumn{2}{|c|}{$\begin{array}{c}\text { Physical Availability of } \\
\text { Food }\end{array}$} \\
\hline & & (8 items, $\left.8-40^{\mathrm{a}}\right)$ & $\mathrm{p}$ & (5 items, $\left.5-25^{\mathrm{a}}\right)$ & $\mathrm{p}$ & (3 items, $\left.3-15^{\mathrm{a}}\right)$ & $\mathrm{p}$ \\
\hline \multicolumn{8}{|l|}{ Gender $(n=1853)^{b}$} \\
\hline Men & $823(44.4)$ & $29.0(25.0,32.0)$ & $<.001$ & $15.0(13.0,18.0)$ & $<.001$ & $13.0(12.0,15.0)$ & .005 \\
\hline Women & $1030(55.6)$ & $30.0(26.0,33.0)$ & & $16.0(14.0,19.0)$ & & $14.0(12.0,15.0)$ & \\
\hline \multicolumn{8}{|l|}{ Age $(n=1853)^{c}$} \\
\hline $20 \mathrm{~s}$ & 183 ( 9.9) & $28.0(26.0,31.0)$ & .34 & $15.0(13.0,17.0)$ & .48 & $13.0(12.0,15.0)$ & .008 \\
\hline $30 \mathrm{~s}$ & $310(16.7)$ & $29.0(26.0,32.0)$ & & $16.0(14.0,18.0)$ & & $13.0(12.0,15.0)^{\mathrm{f}}$ & \\
\hline $40 \mathrm{~s}$ & $300(16.2)$ & $29.0(26.0,32.0)$ & & $16.0(14.0,18.0)$ & & $13.0(12.0,15.0)$ & \\
\hline $50 \mathrm{~s}$ & $329(17.8)$ & $29.0(26.0,33.0)$ & & $16.0(13.0,19.0)$ & & $14.0(12.0,15.0)$ & \\
\hline $60 \mathrm{~s}$ & $385(20.8)$ & $29.0(26.0,33.0)$ & & $16.0(13.0,19.0)$ & & $14.0(12.0,15.0)^{\mathrm{e}}$ & \\
\hline 70 s and older & $346(18.7)$ & $29.0(25.0,32.0)$ & & $16.0(14.0,19.0)$ & & $13.0(12.0,15.0)^{\mathrm{f}}$ & \\
\hline \multicolumn{8}{|c|}{ Living arrangement $(n=1835)^{b}$} \\
\hline Living alone & $145(7.8)$ & $28.0(24.0,31.0)$ & .026 & $15.0(13.0,18.0)$ & .005 & $14.0(12.0,15.0)$ & .57 \\
\hline Living together & $1708(92.2)$ & $29.0(26.0,32.0)$ & & $16.0(14.0,19.0)$ & & $14.0(12.0,15.0)$ & \\
\hline \multicolumn{8}{|l|}{ City size $(n=1853)^{c}$} \\
\hline Tokyo ward area & $99(5.3)$ & $28.0(24.0,30.0)^{\mathrm{e}}$ & $<.001$ & $15.0(12.0,16.0)^{\mathrm{e}}$ & $<.001$ & $13.0(12.0,15.0)$ & .001 \\
\hline $\begin{array}{l}\text { Government-designat } \\
\text { ed cities }\end{array}$ & $336(18.1)$ & $29.0(26.0,32.0)$ & & $15.0(13.0,18.0)^{\mathrm{ef}}$ & & $14.0(12.0,15.0)^{\mathrm{e}}$ & \\
\hline Middle cities $^{\mathrm{d}}$ & $771(41.6)$ & $29.0(25.0,32.0)^{\mathrm{f}}$ & & $16.0(13.0,18.0)^{\mathrm{f}}$ & & $14.0(12.0,15.0)^{\mathrm{e}}$ & \\
\hline Small cities ${ }^{\mathrm{d}}$ & $462(24.9)$ & $29.0(26.0,34.0)^{\mathrm{f}}$ & & $16.0(14.0,19.0)^{\mathrm{g}}$ & & $14.0(12.0,15.0)^{\mathrm{e}}$ & \\
\hline Municipalities & $185(10.0)$ & $29.0(26.0,33.0)^{\mathrm{f}}$ & & $17.0(15.0,20.0)^{\mathrm{g}}$ & & $13.0(11.0,15.0)^{\mathrm{f}}$ & \\
\hline \multicolumn{8}{|c|}{ Frequency of balanced diet $(n=1853)^{c}$} \\
\hline Almost every day & $1302(70.3)$ & $30.0(26.0,33.0)^{\mathrm{e}}$ & $<.001$ & $16.0(14.0,19.0)^{\mathrm{e}}$ & $<.001$ & $14.0(12.0,15.0)^{\mathrm{e}}$ & $<.001$ \\
\hline 4-5 days/week & $281(15.2)$ & $28.0(25.0,31.0)^{\mathrm{f}}$ & & $15.0(13.0,18.0)^{\mathrm{f}}$ & & $13.0(12.0,15.0)^{\mathrm{f}}$ & \\
\hline 2-3 days/week & $192(10.4)$ & $28.0(25.0,30.0)^{\mathrm{f}}$ & & $15.0(13.0,17.0)^{\mathrm{fg}}$ & & $13.0(11.0,14.0)^{\mathrm{f}}$ & \\
\hline Almost never & $78(4.2)$ & $27.0(23.0,31.0)^{\mathrm{f}}$ & & $15.0(12.0,16.0)^{\mathrm{g}}$ & & $13.5(11.0,15.0)$ & \\
\hline \multicolumn{8}{|c|}{ Subjective health $(\mathrm{n}=1853)^{\mathrm{c}}$} \\
\hline Very good & $481(26.0)$ & $30.0(27.0,34.0)^{\mathrm{e}}$ & $<.001$ & $17.0(14.0,20.0)^{\mathrm{e}}$ & $<.001$ & $14.0(12.0,15.0)^{\mathrm{e}}$ & $<.001$ \\
\hline Good & $1016(54.8)$ & $29.0(26.0,32.0)^{\mathrm{f}}$ & & $16.0(13.3,18.0)^{\mathrm{f}}$ & & $13.0(12.0,15.0)^{\mathrm{f}}$ & \\
\hline Fair & $196(10.6)$ & $28.0(24.0,31.0)^{\mathrm{g}}$ & & $16.0(13.0,18.0)^{\mathrm{fg}}$ & & $13.0(11.0,15.0)^{\mathrm{fg}}$ & \\
\hline Not good/Not so good & $160(8.6)$ & $27.0(24.0,30.0)^{\mathrm{g}}$ & & $15.0(13.0,17.0)^{\mathrm{g}}$ & & $12.0(10.0,14.8)^{\mathrm{g}}$ & \\
\hline
\end{tabular}

Note. Median ( $25^{\text {th }}$ and $75^{\text {th }}$ percentile values).

${ }^{\mathrm{a}}$ Range, ${ }^{\mathrm{b}}$ Mann-Whitney U test $(\mathrm{p}<.05),{ }^{\mathrm{c}}$ Kruskal-Wallis test $(\mathrm{p}<.05),{ }^{\mathrm{d}}$ Middle cities: population $\geq 100000$, Small cities: population $<100000,{ }^{e, f, g}$ Different letters (e, f, g) show a significant difference in Bonferroni multiple comparisons $(p<.05)$. 


\section{Discussion}

This study confirmed the reliability and validity of the PNFE scale, which consists of eight items with two factors ("regional food culture" and "physical availability of food"). While the PNFE total score can be used, we propose utilizing each subscale because the criterion-related validity results of each subscale were different.

The "regional food culture" subscale evaluates food-related regional linkages and includes resources of social capital (SC) related to food, such as social support and participation in neighborhood organizations. The theory that $\mathrm{SC}$ is the aggregate of resources is based on theories by Bourdieu (1986), which is a useful approach when considering how neighbors and regions affect residents' health (Kawachi, Subramanian, \& Kim, 2008). It makes sense that "regional food culture" scores were higher for those living together than for single persons, as previous studies have shown that married people share food with neighbours, chat together, and exchange lifestyle information. Additionally, unmarried or childless people often make little effort to participate in town events (Nagaishi et al., 1997). It is also reasonable that "regional food culture" scores decreased as city size increased. In urban areas where there are many salaried households, dilution of neighborhood relations occurs because salaried workers spend limited time in their living area (Ministry of Internal Affairs and Communications, 2014).

The "physical availability of food" subscale includes items used for the observational or geographical measurement of the conventional food environment, such as availability of food and access to grocery stores. Previous studies related food access to eating behaviour (Iwama et al., 2016; Moore et al., 2008; Yoshiba et al., 2015), which is an important factor in evaluating food environments. For city size, "physical availability of food" was lower for municipal residents. This was consistent with previous findings indicating that rural residents had difficulty accessing stores with wide food selections compared to urban residents (Yakushiji \& Takahashi, 2013).

This study has four limitations. A limitation of this research was that it targeted only those who responded to individual interviews. The response rates for men and women in their 20 s were low, and there might have been biases in the degree of interest in food. Participants with diverse characteristics should be examined in the future. Further, the items were limited because of our use of existing questions. Other items could be included in this scale, such as food prices (Green \& Glanz, 2015) and co-eating opportunities in the area (Kimura et al., 2012). In addition, future studies will need to examine the relationship between the PNFE scale and an objective dietary environment. Furthermore, comparing the PNFE and NEMS-P would increase the validity of the scale.

\subsection{Conclusion}

We confirmed the reliability and validity of the PNFE scale, which includes the concept of food-related SC. The scale captures how local residents perceive the present condition of their food environment, including both physical availability and food-related regional connections. This enables the identification of problems in the local food environment and development of interventions or health promotions. Therefore, this scale could contribute to improving food environments and revitalizing local communities. By utilizing it for future research in other countries, it is expected that its reliability and validity for a wider range of residents will be confirmed. In addition, consideration should be given to the items used for confirming the validity of the scale in the next study to ensure that they are appropriate for other countries included in the research.

\section{Acknowledgments}

The data for this secondary analysis, 'The Survey of the Current Status and Awareness of Shokuiku, 2010, Office for the Food Education Promotion, Cabinet Office, Government of Japan', were provided by the Social Science Japan Data Archive, Center for Social Research and Data Archives, Institute of Social Science, the University of Tokyo. This work was supported by JSPS KAKENHI Grant Number 18K02219.

\section{References}

Ainuki, T., Akamatsu, R., Hayashi, F., \& Takemi, Y. (2012). The reliability and validity of the Subjective Diet-related Quality of Life (SDQOL) Scale among Japanese Adults [in Japanese]. The Japanese Journal of Nutrition and Dietetics, 70(3), 181-187. https://doi.org/10.5264/eiyogakuzashi.70.181

Bourdieu, P. (1986). The forms of capital. In J. G. Richardson (Ed.), Handbook of theory and research for the sociology of education (pp. 241-58). New York: Greenwood Press.

Cannuscio, C. C., Tappe, K., Hillier, A., Buttenheim, A., Karpyn, A., \& Glanz, K. (2013). Urban food environments and residents' shopping behaviors. American Journal of Preventive Medicine, 45(5), 606-614. https://doi.org/10.1016/j.amepre.2013.06.021

Glanz, K., Johnson, L., Yaroch, A. L., Phillips, M., Ayala, G. X., \& Davis, E. L. (2016). Measures of retail food store environments and sales: Review and implications for healthy eating initiatives. Journal of Nutrition 
Education and Behavior, 48(4), 280-288. https://doi.org/10.1016/j.jneb.2016.02.003

Green, S.H., \& Glanz, K (2015). Development of the Perceived Nutrition Environment Measures Survey. American Journal of Preventive Medicine, 49(1), 50-61. https://doi.org/10.1016/j.amepre.2015.02.004

Health Sciences Council. (2012). Reference material on promotion of Health Japan 21 (the second term) [in Japanese]. Retrieved from https://www.mhlw.go.jp/bunya/kenkou/dl/kenkounippon21_02.pdf

Iwama, N., Asakawa, T., Tanaka, K., \& Komaki, N. (2016). Improving the food deserts map based on food accessibility and social capital to understand factors affecting the dietary conditions of elderly residents: Case study of the center of a local city [in Japanese]. E-journal GEO, 11(1), 70-84.

Kakutani, Y., Kamiya, S., \& Omi, N. (2015). Association between the frequency of meals combining "Shushoku, Shusai, and Hukusai" (staple food, main dish, and side dish) and intake of nutrients and food groups among Japanese young adults aged 18-24 years: a cross-sectional study. Journal of Nutritional Science and Vitaminology, 61(1), 55-63. https://doi.org/10.3177/jnsv.61.55

Kawachi, I., Subramanian, S. V., \& Kim, D. (Eds.). (2008). Social capital and health [in Japanese]. Tokyo: Nihon Hyoronsha.

Kimura, Y., Wada, T., Okumiya, K., Ishimoto, Y., Fukutomi, E., Kasahara, Y., \& Matsubayashi, K. (2012). Eating alone among community-dwelling Japanese elderly: Association with depression and food diversity [in Japanese]. The Journal of Nutrition, Health \& Aging, 16(8), 728-731. https://doi.org/10.1007/s12603-012-0067-3

Kurotani, K., Akter, S., Kashino, I., Goto, A., Mizoue, T., Noda, M., \& Tsugane, S. (2016). Quality of diet and mortality among Japanese men and women: Japan Public Health Center based prospective study. BMJ, 352, https://doi.org/10.1136/bmj.i1209

Ministry of Health, Labour and Welfare. (2012). A basic direction for comprehensive implementation of national health promotion. Retrieved from https://www.mhlw.go.jp/file/06-Seisakujouhou-10900000-Kenkoukyoku/0000047330.pdf

Ministry of Internal Affairs and Communications. (2014). Study group report on future communities in urban areas [in Japanese]. Retrieved from http://www.soumu.go.jp/main_content/000284117.pdf

Moore, L. V., Diez Roux, A. V., Nettleton, J. A., \& Jacobs, D. R., Jr. (2008). Associations of the local food environment with diet quality - A comparison of assessments based on surveys and geographic information systems: The multi-ethnic study of atherosclerosis. American Journal of Epidemiology, 167(8), 917-924. https://doi.org/10.1093/aje/kwm394

Nagaishi, K., Asada, S., Adachi, K., Enami, H., Endou, M., Senou, K., \& Fujita, R. (1997). The influence of family and residence: The present state and problems of social networks in Chugoku-Shikoku District (Part 4) [in Japanese]. Journal of Home Economics of Japan, 48(9), 763-773. https://doi.org/10.11428/jhej1987.48.763

Office for Shokuiku Promotion. (2011). The survey of the current status and awareness of shokuiku, 2010 [in Japanese]. $\quad$ Retrieved from http://warp.da.ndl.go.jp/info:ndljp/pid/9929094/www8.cao.go.jp/syokuiku/more/research/h23/h23/index.ht $\mathrm{ml}$

Oshio, S. (2008). First analysis of covariance structure: Pass analysis with Amos [in Japanese]. Tokyo: Tokyo Tosho.

Public Health England. (2017). Salt reduction targets for 2017. Retrieved from https://assets.publishing.service.gov.uk/government/uploads/system/uploads/attachment_data/file/604338/S alt_reduction_targets_for_2017.pdf

Yakushiji, T., \& Takahashi, K. (2013). Accessibility to grocery stores in Japan - A comparison between urban and rural areas by measuring the distance to stores [in Japanese]. Journal of Food System Research, 20(1), 14-25. https://doi.org/10.5874/jfsr.20.14

Yakushiji, T., Takahashi, K., \& Tanaka, K. (2013). Difficulties in accessing food from local residents' viewpoint: Factors of inconvenience and laboriousness involved in shopping for food [in Japanese]. Journal of Rural Economics, 85(2), 45-60. https://doi.org/10.22004/ag.econ.242289

Yoshiba, K., Takemi, Y., Ishikawa, M., Yokoyama, T., Nakaya, T., \& Murayama, N. (2015). Relationship between dietary diversity and food access among elderly living alone in Saitama Prefecture [in Japanese]. Nihon 
Koshu Eisei Zasshi [Japanese Journal of Public Health], 62(12), 707-718. https://doi.org/10.11236/jph.62.12_707

\section{Copyrights}

Copyright for this article is retained by the author(s), with first publication rights granted to the journal.

This is an open-access article distributed under the terms and conditions of the Creative Commons Attribution license (http://creativecommons.org/licenses/by/4.0/). 